\title{
Response to the future of the EANS neurosurgeons of Europe, unite!
}

\author{
Vladimír Beneš $^{1} \cdot$ André Grotenhuis $^{1} \cdot$ Johannes Schramm $^{1} \cdot$ Andras Buki $^{1}$ • \\ Nejat Akalan ${ }^{1}$. Toomas Asser ${ }^{1}$. Jannick Brennum ${ }^{1}$ - Shlomi Constantini ${ }^{1}$. \\ Domenico D'Avella ${ }^{1}$ • Peter Hutchinson ${ }^{1}$ - Johannes van Loon ${ }^{1}$
}

Received: 19 August 2015 / Accepted: 20 August 2015 /Published online: 3 September 2015

(C) Springer-Verlag Wien 2015

The letter from Professor Bartels calls for the transformation of the EANS into a purely individual membership society. This is perfectly legitimate and raises an important issue, which we in the EANS leadership have discussed at length over the last few years. Quite aside from the specific motion and content raised in the letter, we have encouraged the development of a mature and interactive association, which represents neurosurgeons, primarily in Europe but also worldwide, in a "bottom-up" fashion. As such, we fully acknowledge Prof. Bartels' letter as an important trigger for a serious discussion.

Originally founded in 1971 as a federation representing national European neurosurgical societies, the EANS decided just under a decade ago to introduce the opportunity for individual membership. Since then, the EANS has steadily increased its individual membership, while remaining fully committed to serving the needs of its national society members. We now have some $1300 \mathrm{IMs}$, of which nearly 250 are from non-EANS countries. The remaining ca. 1050 members within EANS countries represent around 15\% of all European neurosurgeons, and we have IMs in nearly all EANS member countries. The activity and influence of our individual members has increased significantly in recent years, not only in terms of numbers, but also as a result of increased voting capacity, access to educational material, and other benefits. We believe that this process will continue in the coming years.

Vladimír Beneš

vladimir.benes@uvn.cz

1 Department of Neurosurgery, Charles University, Prague, Czech Republic
The role of the EANS in respect of its national society members continues to have tremendous importance. Many members of these societies are unable to join the EANS as IMs for various reasons. Through their national society membership, however, they are both represented within the EANS and exposed to its activities. The fact that EANS represents national societies provides our community with a much stronger voice, and through UEMS activities, affords us significantly more influence upon EU commissions. The role of our JRAAC (Joint Residency Advisory and Accreditation Committee) in dealing with educational progammes and accreditations bridges EANS and UEMS activities and is institutional and related to national societies. The postgraduate system created by the EANS has been adopted by many national societies and is now the acknowledged basis for neurosurgical education within Europe. The close interaction between the Association and its member societies is a significant factor in the strength of the programme.

In his letter, Prof. Bartels mentions that "the influence of the EANS on national neurosurgical care is nihil. Within our national society, I have never seen or heard of any major development that was initiated by the EANS". From his perspective in The Netherlands, this may seem true.

However, it is not, and has never been, within the mandate of the EANS to initiate developments within national societies. The main reason that EANS cannot influence or initiate new regulations is the EU's nation states' decision to retain regulatory powers in respect of health care issues, rather than delegating these to the $\mathrm{EU}$, as is the case in respect of human rights and consumer affairs. As a consequence, the role of EANS initiatives such as JRAAC is limited to making proposals and recommendations. A comparison between the current EANS and the European Union "without its authorities" is therefore undeserved, since the EANS was founded to support member societies, not to rule over them. 
Out of this endeavor, the Training Courses have been developed, offering a 4-year neurosurgical curriculum for residents of all member societies. While some countries (e.g., the Scandinavian countries, Germany, The Netherlands) already had their own national training courses, this initiative was of enormous benefit for many other member societies. Indeed, even those countries, which have their own national courses, choose to send trainees to the EANS Training Course. Furthermore, the EANS is well placed to support member societies in their struggle with national authorities, for example in respect of discussions as to minimum requirements for neurosurgical practice. Again, some of our member societies do not need such help, but the same is true within Europe, where some countries are faring well, while others need help. There are many reasons why the European Union has not changed into the United States of Europe, in which all individuals are simply Europeans.
The decision to relinquish our federation status and connection with the national societies would lead directly to the loss of two European votes within the WFNS, while the Association's political impact within Europe would be similarly reduced. We therefore believe that the prestige and political influence of the EANS would be diminished by transforming the association into an individual membership society.

We will continue to discuss this important subject within the association and actively welcome new ideas and proposals for new directions. At present, however, the relevant constituency are the founding members - national societies, not the individual members. We believe that we have the best of both worlds as an association of societies that also embraces Individual Members. In our opinion, the interests of European neurosurgery are best served by retaining the European Association of Neurosurgical Societies rather than transforming it to the European Neurosurgical Society. 